\title{
Análise da Geração Eólica na Matriz Brasileira de Energia Elétrica
}

\section{Analysis of Wind Power Generation in Brazilian Power Electric Matrix}

\author{
Giuliano Arns Rampinelli \\ Departamento de Engenharia Elétrica \\ Faculdade SATC, Criciúma, SC \\ giuliano.rampinelli@satc.edu.br \\ Celso Generoso da Rosa Junior \\ Departamento de Engenharia Elétrica \\ Faculdade SATC, Criciúma, SC \\ celsojunior182@gmail.com
}

Resumo: A gradual inserção de energias renováveis auxilia na diversificação da matriz e amplia a segurança energética do país. Entre as diversas fontes renováveis, a energia eólica se sobressai no mundo e avança em ritmo acelerado, em função de seu desenvolvimento tecnológico de eficiência, incentivos fiscais e rentabilidade de investimento. Entretanto, a inserção em grande escala da geração eólica na rede elétrica pode causar determinados problemas no sistema de eletricidade. Este trabalho apresenta um panorama da energia eólica no Brasil e no mundo, sua integração com outras fontes de energia, uma análise dos impactos da geração eólica na matriz energética brasileira e uma breve descrição da participação da energia eólica na Espanha.

Palavras-chave: controle e código de rede; geração eólica; impactos na rede; matriz de energia elétrica.

Abstract: The gradual integration of renewable energy helps diversify the matrix and expands the country's energy security. Among the various sources of renewable generation, wind generation stands out in the world and advances at a rapid

Recebido em 11/04/2013 - Aceito em 16/06/2013.

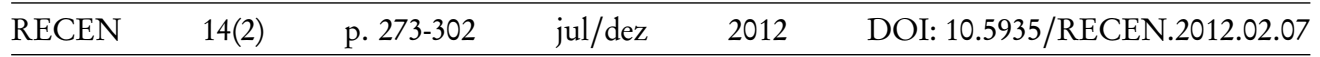


pace, due to its technological efficiency, tax incentives and investment profitability. However, the large scale integration of wind generation in the grid can cause certain problems in the electricity system. This paper presents an overview of wind energy in Brazil and in the World, its integration with other energy sources, an analysis of the impacts of wind generation in the Brazilian energy matrix and a brief description of the participation of wind power in Spain.

Key words: control and network code; eletric power matrix; impacts on the network; wind power.

\section{Introdução}

Atualmente, a energia eólica tem sido utilizada em grande escala no mundo por ser uma tecnologia de geração de energia elétrica renovável, competitiva e confiável. A causa disto é sua relação custo-benefício e sua tecnologia avançada, sendo que a sua expansão é explicada, em parte, pela necessidade global de diversificação da matriz de energia elétrica a fim de torná-la mais limpa, diminuindo os problemas ambientais e mais segura. No Brasil, a geração eólica teve seu impulso através de incentivos fiscais e leilões voltados à sua comercialização. A tecnologia eólica é empregada há pouco tempo no país, mas sua participação já atinge valores significativos na matriz de energia elétrica nacional e seu crescimento é acentuado nos últimos anos. Entretanto, a variabilidade da geração eólica tem sido muito questionada, levando em conta sua influência no controle do sistema integrado nacional devido à sua intermitência de geração, ocasionada pela variabilidade dos ventos, principalmente no nordeste e no sul - regiões com maior concentração de parques eólicos - e também

por ela ser uma energia de caráter complementar à matriz elétrica base (hidráulica, térmica e termonuclear).

\section{Geração eólica}

No final do século XX e início do século atual, a questão energética tornou-se foco de debates da comunidade científica e sociedade organizada, devido a dois fato- 
res de grande impacto: o aumento no consumo de combustíveis fósseis do mundo e os impactos ambientais relevantes ocasionados pela sua utilização. A Terra apresenta diversos recursos energéticos exploráveis, sendo que esses podem ser provenientes de fontes renováveis, em que se destacam o aproveitamento da energia eólica, hidráulica, solar e biomassa, ou originários de fontes não renováveis, como petróleo, carvão, gás natural e nuclear.

A utilização de fontes renováveis de geração de energia surge como alternativa para a redução dos impactos ambientais dos combustíveis fósseis e para o suprimento de parte da demanda crescente de energia elétrica. Um dos problemas para o crescimento da participação dessas fontes na matriz de energia são os altos custos tecnológicos agregados a elas, tornando algumas inviáveis economicamente. Para que essas barreiras sejam superadas tornando-as competitivas, são necessários incentivos governamentais e investimento em pesquisa e desenvolvimento.

\subsection{Matriz energética mundial e brasileira}

A matriz energética de cada país relaciona-se diretamente com a sua disponibilidade energética, ou seja, com os recursos energéticos disponíveis em seu território. O potencial energético de um país depende de seus recursos naturais e do conhecimento sobre eles, como também do aproveitamento e condições de sua recuperação [1]. Atualmente, a matriz energética mundial apresenta, como sua principal fonte de geração de energia, os combustíveis fósseis que correspondem a aproximadamente $80,9 \%$ da matriz. A participação de fontes renováveis é de aproximadamente $12,9 \%$ enquanto a energia nuclear representa cerca de 5,8\%. A figura 1 apresenta o cenário mundial de oferta de energia em 2009.

No Brasil, esse cenário tem uma realidade diferente, conforme o Balanço Energético Nacional (BEN - 2012), 44,1\% da matriz energética brasileira é proveniente de energias renováveis, o que está muito acima da média mundial que é 13,3\%. A tabela 1 apresenta a matriz de energia do Brasil.

A matriz de energia elétrica no Brasil apresenta atualmente capacidade instalada de aproximadamente 127,65 GW, sendo que a energia hidráulica responde por cerca de 65,29\% dessa potência. A tabela 2 apresenta a participação das fontes de energia 
Revista Ciências Exatas e Naturais, Vol.14, n² Jul/Dez 2012

que compõem a matriz de energia elétrica brasileira.

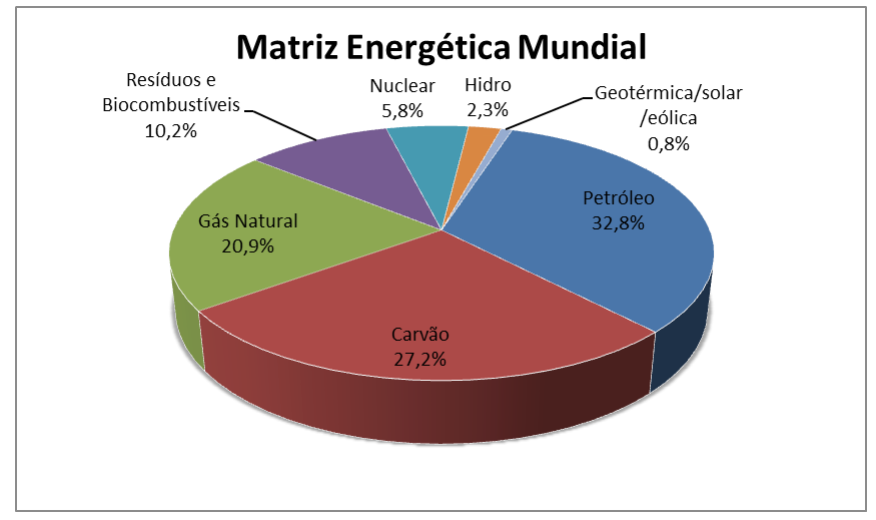

Figura 1. Cenário mundial de oferta de energia em 2009 [2].

Tabela 1. Matriz energética brasileira [3].

\begin{tabular}{cc}
\hline Fontes & Percentual na Matriz Energética Brasileira \\
\hline Biomassa de cana & $15,70 \%$ \\
Hidráulica e eletricidade & $14,70 \%$ \\
Lenha e Carvão Vegetal & $9,70 \%$ \\
Lixo e outras renováveis & $4,10 \%$ \\
Petróleo e derivados & $38,60 \%$ \\
Gás Natural & $10,10 \%$ \\
Carvão Mineral & $5,60 \%$ \\
Urânio & $1,50 \%$ \\
\hline
\end{tabular}

Tabela 2. Matriz elétrica brasileira [4].

\begin{tabular}{cc}
\hline Fontes & Percentual instalado na Matriz Elétrica Brasileira \\
\hline Hidráulica & $65,29 \%$ \\
Biomassa & $7,64 \%$ \\
Gás Natural & $10,48 \%$ \\
Nuclear & $1,57 \%$ \\
Derivados de Petróleo & $5,74 \%$ \\
Carvão e Derivados & $1,52 \%$ \\
Eólica & $1,35 \%$ \\
Importação & $6,40 \%$ \\
\hline
\end{tabular}

No Brasil, também ocorreu o incentivo governamental para a utilização das 
energias alternativas, principalmente através do Programa de Incentivo às Fontes Alternativas de Energia Elétrica (PROINFA), o qual é gerenciado pela Eletrobrás. O PROINFA tem como meta uma participação de $10 \%$ das energias por fontes alternativas na matriz elétrica brasileira.

\subsection{Matriz de energia elétrica brasileira}

No que se refere à matriz elétrica brasileira, o crescimento da energia eólica aparece com percentuais destacáveis em relação ao crescimento de outras fontes de energia, mas ainda faz parte de uma pequena parcela. O Brasil, além de ser muito favorável a energia eólica, tem sua matriz imensamente dominada pela geração hídrica, que também tem em solo brasileiro uma geografia extremamente favorável, sendo esta responsável por mais de $80 \%$ da geração nacional e com mais de $65 \%$ da capacidade instalada (Figura 2). Outro ponto relevante é a importância que a energia eólica está tomando na matriz, levando-se em conta suas projeções, pois se espera que em 2020 aproximadamente $10 \%$ da capacidade instalada do Brasil seja do aproveitamento da energia eólica, o que a tornaria a segunda principal fonte de energia elétrica.

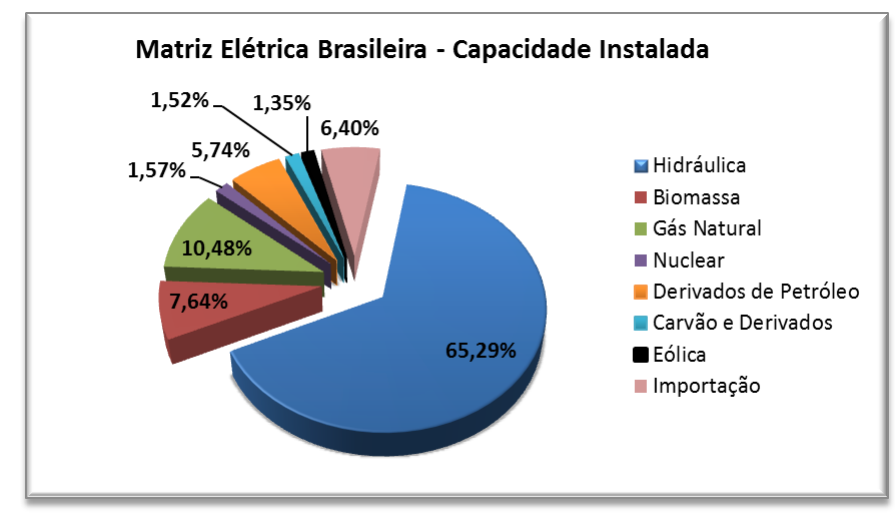

Figura 2. Capacidade instalada da matriz de energia elétrica brasileira [3].

Entretanto, o fator de capacidade da geração eólica, ou seja, a média mensal de sua geração é entre $26 \%$ e $40 \%$ da capacidade instalada, devido às médias de vento anuais da região do empreendimento. Assim, existe uma grande diferença entre a 
Revista Ciências Exatas e Naturais, Vol.14, n², Jul/Dez 2012

capacidade instalada e gerada na energia eólica, o que ocorre de forma controlável em usinas hidroelétricas ou térmicas, que podem trabalhar com um fator de capacidade elevado. A figura 3 apresenta a geração de energia elétrica por fonte na matriz brasileira.

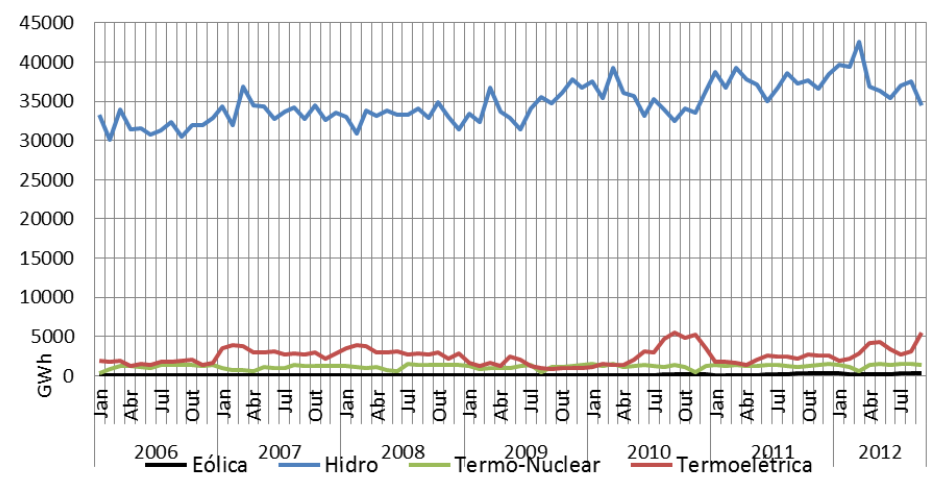

Figura 3. Matriz elétrica brasileira - Geração [5].

Desconsiderando a geração hídrica que é a principal fonte de energia elétrica brasileira, a geração eólica vem apresentando um crescimento contínuo, embora sua participação ainda seja pequena, mas que tende a ser significativa no transcorrer da década atual. A figura 4 apresenta a geração de energia elétrica por fonte, mas desconsiderando a energia hidráulica.

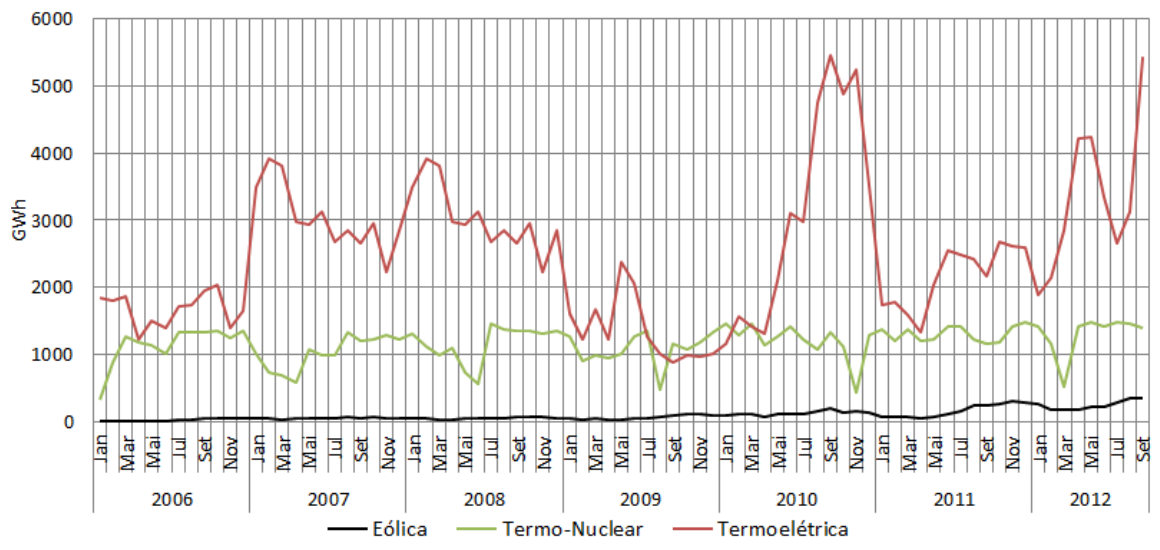

Figura 4. Matriz elétrica brasileira sem dados hídricos - Geração [5]. 


\subsection{Geração interligada ao sistema elétrico brasileiro}

A geração de energia elétrica no Brasil através da geração eólica tem sua origem no ano de 2002, a partir do PROINFA, criado no âmbito do Ministério de Minas e Energia (MME), pela Lei ${ }^{o} 10.438$, de 26 de abril de 2002, e revisado pela Lei ${ }^{o}$ 10.762, de 11 de novembro de 2003. O PROINFA é um programa governamental com o intuito de diversificar a matriz elétrica brasileira através de fontes alternativas de energia. Pode-se afirmar que foi por meio de decisões políticas que o Brasil abriu suas portas para a energia eólica. Até a sua criação, havia somente aerogeradores para pesquisas acadêmicas ou em pontos onde não existiam linhas de transmissão e distribuição de energia [6].

Por meio desses incentivos e de uma série de medidas tomadas para facilitar a viabilização desses projetos como a realização de leilões específicos, a energia eólica ganhou participação no Brasil. Os leilões de energia são iniciativas recentes, resultado do novo modelo do setor elétrico implantado em 2012. A cada ano, o país precisa contratar mais fontes de energia para atender às suas demandas e os leilões servem para unir geradores de energia e distribuidoras. Os leilões de energia funcionam de maneira reversa. Ele é iniciado com um preço máximo e vai decrescendo ao longo do processo. A ANEEL é a instituição responsável pela condução dos procedimentos licitatórios. Os valores da energia eólica no PROINFA foram da ordem de R\$298,00/MWh. Esses valores são bem maiores quando comparados aos valores das fontes convencionais de energia, que são da ordem de $\mathrm{R} \$ 100,00 / \mathrm{MWh}$. Entretanto, devido aos incentivos governamentais através do programa, esses preços foram reduzidos consideravelmente. Tais incentivos e preços atraíram empresas da área que, devido a crise mundial e à necessidade de se expandir a novos mercados, investiram fortemente no mercado brasileiro, montando parques e fábricas de componentes e aerogeradores para as usinas eólicas.

Uma série de fatores como o investimento de capital estrangeiro, incentivo fiscal e perspectivas de expansão em solo brasileiro devido à pouca exploração do seu grande potencial eólico, tornou o mercado de geração eólico brasileiro competitivo e de grande crescimento. Esse cenário favorável à energia eólica pode ser verificado 
nos leilões seguintes, que se tornaram anuais e com grandes reduções nos valores da energia contratada, chegando a valores da ordem de R\$100,00/MWh no LER de 2011.(Tabela 3) [6, 7].

Tabela 3. Leilões de energia eólica.

\begin{tabular}{ccc}
\hline $\begin{array}{c}\text { Venda da } \\
\text { energia eólica }\end{array}$ & $\begin{array}{c}\text { Potência instalada } \\
\text { negociada }\end{array}$ & $\begin{array}{c}\text { Valores médios } \\
\text { do MWh (R\$) }\end{array}$ \\
\hline PROINFA & $1.423 \mathrm{MW}$ & 298,00 \\
LER 2009 & $1.805 \mathrm{MW}$ & 148,39 \\
A-3 2010 & $1.685 \mathrm{MW}$ & 134,10 \\
LER 2010 & $2.047 \mathrm{MW}$ & 122,69 \\
A-3 2011 & $1.929 \mathrm{MW}$ & 101,64 \\
LER 2011 & $1.929 \mathrm{MW}$ & 99,59 \\
A-5 & $976,5 \mathrm{MW}$ & 105,53 \\
\hline
\end{tabular}

O Brasil como país em desenvolvimento, possui uma demanda crescente de energia que, segundo a EPE (Empresa de Pesquisa Energética), necessitará anualmente de um incremento médio de $3200 \mathrm{MW}$, até 2020. Com isso, existe a necessidade do constante aumento da capacidade instalada na matriz elétrica brasileira. A descentralização da geração de energia é também um considerável benefício, pois torna a geração mais próxima dos centros consumidores, reduzindo as perdas e investimentos em linhas de transmissão e distribuição. O incentivo à micro e mini geração de energia deve ser permanente. Outro fator de extrema importância para o sistema elétrico brasileiro é a complementaridade entre as fontes eólicas e hídricas, que devido à sua sazonalidade, necessita de complementação e que tende a crescer com o passar dos anos, em função das exigências ambientais que preveem diminuição dos reservatórios das novas usinas hidroelétricas [8].

Atualmente, o parque de energia eólica brasileiro apresenta potência instalada de aproximadamente $1.800 \mathrm{MW}$, porém se projeta uma potência instalada de 7.200 MW até 2014 e a contratação de aproximadamente 2.000 MW por ano em leilões, com o intuito de alcançar uma capacidade instalada de 20.000 MW em 2020. Para o adequado aproveitamento da energia eólica, é necessário uma série de análises técnicas com o objetivo de viabilizar o projeto. As medições de velocidade de vento 
por períodos mínimos estabelecidos em projeto são fundamentais para que seja estimado o potencial eólico de uma determinada região. No Brasil foi desenvolvido um atlas do potencial eólico [9]. Porém, atualmente este não é considerado como base de dados, devido aos métodos de medições utilizados em sua elaboração que não atendem devidamente às características da tecnologia de geração atual. Por exemplo, a altura no qual foram coletados os dados de velocidade de vento $(50 \mathrm{~m})$ é a metade da altura em que os aerogeradores são instalados atualmente $(100 \mathrm{~m})$. Entretanto, esses estudos servem para indicar, de forma genérica, as regiões com melhor potencial eólico. O Brasil apresenta um excelente recurso eólico, principalmente em seu litoral e se caracteriza por possuir uma média anual duas vezes maior que a média mundial e uma oscilação baixa de velocidade de vento, o que facilita as previsões de energia a ser gerada $[8,9]$.

\subsection{Regiões precursoras na geração eólica no Brasil}

A partir dos requisitos citados, duas regiões brasileiras se destacam: nordeste e sul. Para que um parque eólico seja viável são necessários que sejam analisados inúmeros fatores. Por exemplo, os valores anuais de velocidade de vento devem ser superiores a $6 \mathrm{~m} / \mathrm{s}$. Uma importante ferramenta que fornece informações de velocidade de ventos é o atlas do potencial eólico brasileiro, que apresenta mapas dos regimes de vento e fluxos de potência eólica na altura de 50 metros para todo o país[10]. As regiões nordeste e sul se destacam do restante do Brasil por terem, em alguns pontos específicos, médias anuais de 7 a $8,5 \mathrm{~m} / \mathrm{s}$ [10]. A figura 5 apresenta a divisão da potência eólica instalada entre as duas regiões. Verifica-se que aproximadamente $63,4 \%$ da potência eólica está instalada no nordeste brasileiro enquanto que cerca de $36,6 \%$ da potência eólica está na região sul do Brasil.

A energia eólica brasileira começou a gerar valores consideráveis de energia aproximadamente na metade de 2006, através do PROINFA, já estando no Sistema Interligado Nacional (SIN). Desse considerável princípio até aproximadamente a metade de 2009, principalmente devido ao maior parque eólico até então instalado no Brasil, em Osório, RS, com 75 máquinas de $2 \mathrm{MW}$ cada, o sul brasileiro dominava a geração eólica nacional, porém os investimentos no nordeste através dos 
Revista Ciências Exatas e Naturais, Vol.14, n², Jul/Dez 2012

leilões posteriores ao PROINFA elevaram consideravelmente sua capacidade e geração, como é possível analisar na figura 6, conforme dados do Operador Nacional do Sistema [5].

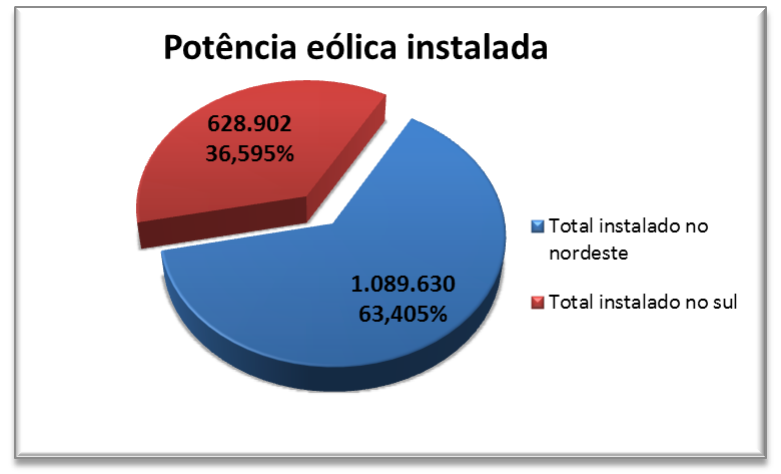

Figura 5. Comparação das potências instaladas no nordeste e sul do Brasil [8].

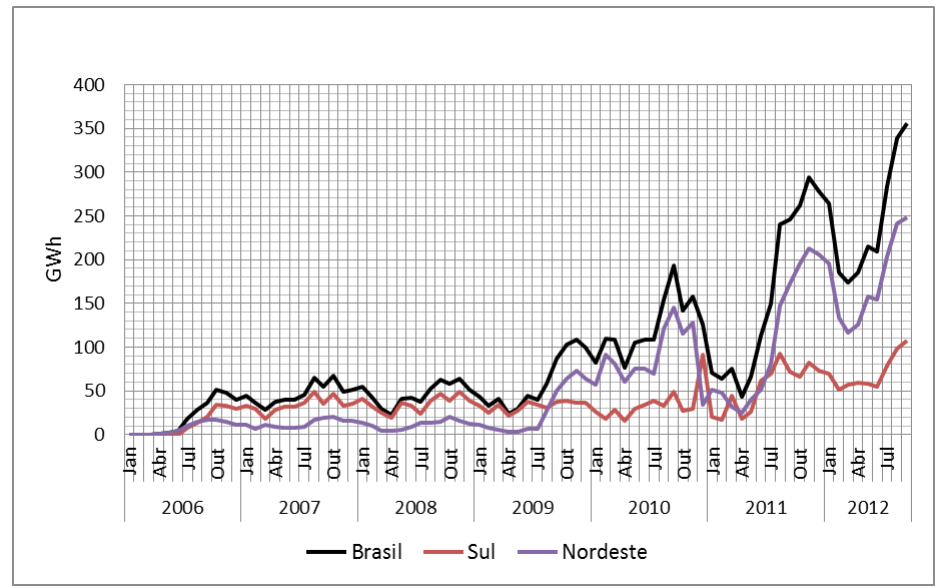

Figura 6. Geração eólica no Brasil [5].

\subsection{Geração complementar - hídrica e eólica}

A geração hidroelétrica tem grande potencial no Brasil, devido a imensidão de alternativas hídricas para a implantação de usinas, porém grande parte dos afluentes com potencial explorável se encontra no Norte do país, na região da floresta 
amazônica que, por questões ambientais, não permite a formação de reservatórios com grande capacidade de água. Como alternativa são empregadas nessas regiões usinas hidrelétricas a fio d'água, tornando o sistema cada vez mais sazonal. O problema que se obtém, nas usinas instaladas em áreas sem grandes reservatórios, é que em períodos de seca, sua geração fica muito abaixo do seu potencial, que somente será alcançado nos períodos úmidos.

Devido a esses problemas, que devem aumentar com os anos pela expansão da geração hídrica na Amazônia, tem-se a necessidade da geração complementar de energia elétrica, em que a geração eólica se encaixa perfeitamente, pois comumente a sazonalidade dos ventos é inversa à sazonalidade do regime de chuvas. Essa sazonalidade inversa dessas duas fontes de energia ocorre de forma destacável no nordeste brasileiro, onde a capacidade eólica é a maior do país. Nessa região, os melhores ventos anuais e, consequentemente, a maior geração, ocorrem entre junho e novembro, ou seja, período de baixas afluências. (Figura 7).

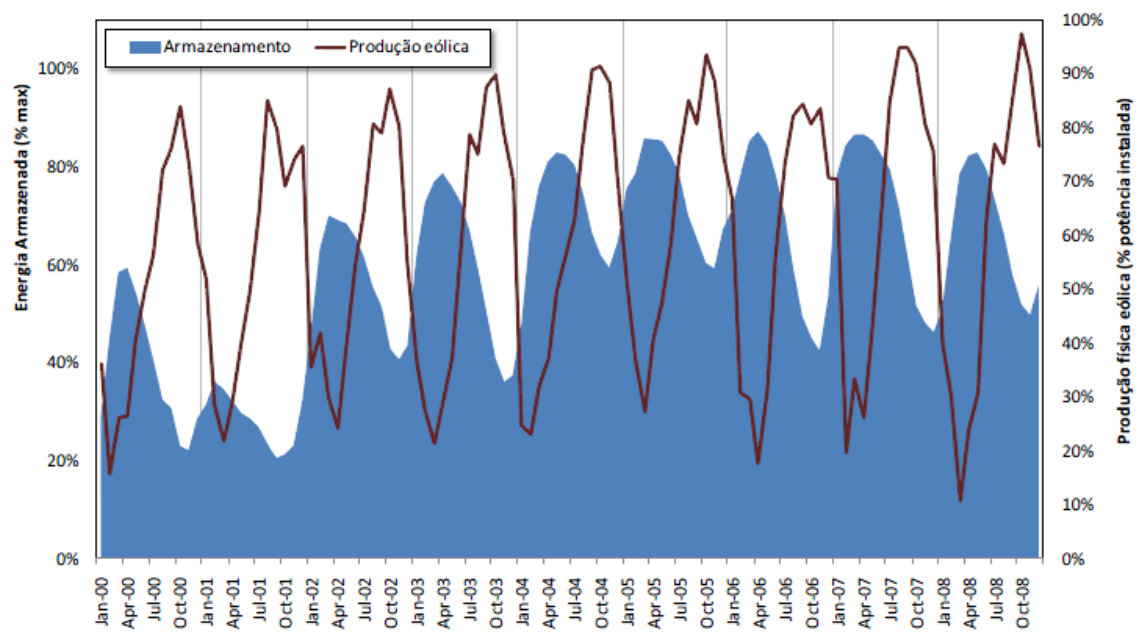

Figura 7. Complementaridade geração bídrica e eólica [11].

No Sul do Brasil, existe concomitância entre a sazonalidade hídrica e sazonalidade dos ventos, o que aumenta a potência gerada nessa região, porém essas fontes não apresentam complementaridade. Para um planejamento de sistemas elétricos em longo prazo, a confiabilidade geral do sistema considera se a capacidade de ge- 
ração comporta a demanda de energia do sistema. Assim, pode-se afirmar que a inserção da geração eólica no sistema, torna-o mais confiável como um todo, pois permite que reservatórios sejam mantidos cheios enquanto a eólica está gerando eletricidade, mesmo não sendo uma forma de geração despachável [12].

\subsection{Geração complementar - solar e eólica}

Outra fonte com características favoráveis à complementação com a eólica é a energia solar. A radiação solar possui um comportamento previsível durante o dia, diferentemente dos ventos, a qual inicia o dia com valores baixos, tem seu pico ao meio dia, decrescendo até o fim de tarde. Porém, é importante ressaltar que essas situações ocorrem em dias de céu limpo (sem nebulosidade). O comportamento da radiação solar que atinge a superfície terrestre depende do índice de nebulosidade que varia significativamente ao longo dos dias. A energia eólica apesar de menos previsível, possui uma velocidade média dos ventos mais elevadas em horários em que a incidência da radiação solar é baixa, como no final de tarde e no início da madrugada, como pode ser verificado na figura 8. Portanto a avaliação anual da complementaridade solar-eólica é mais confiável. Assim, ambas as fontes tem sua utilização em conjunto favorecidas.

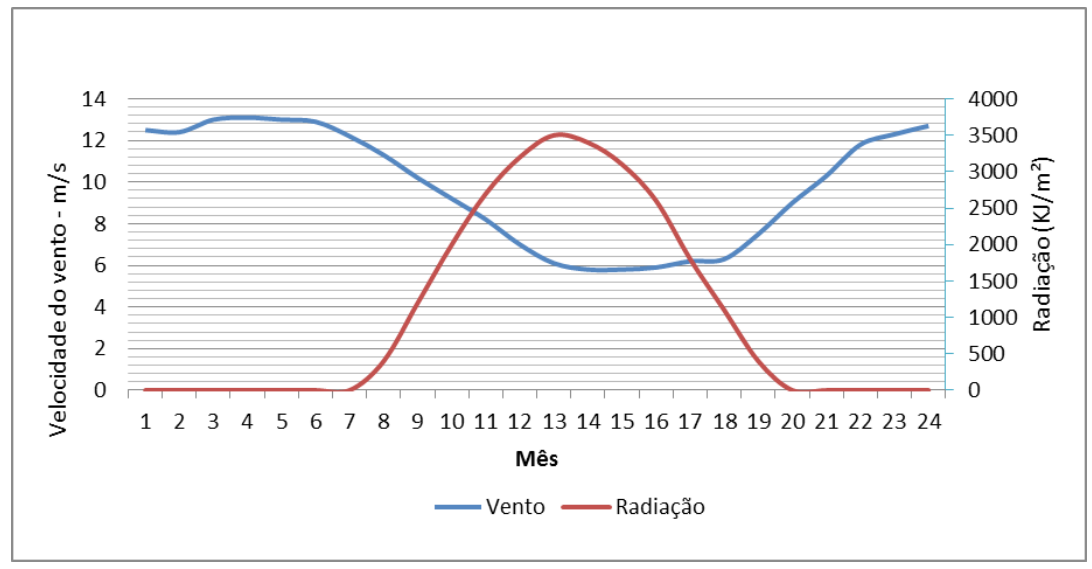

Figura 8. Complementaridade solar e eólica diariamente (melhor hipótese)[11]

Além da complementaridade diária da geração solar e eólica, anualmente, tam- 
bém existe uma sazonalidade inversa entre as duas fontes de energia. A figura 9 apresenta a velocidade de vento média e a irradiância média ao longo do ano para a região nordeste [11].

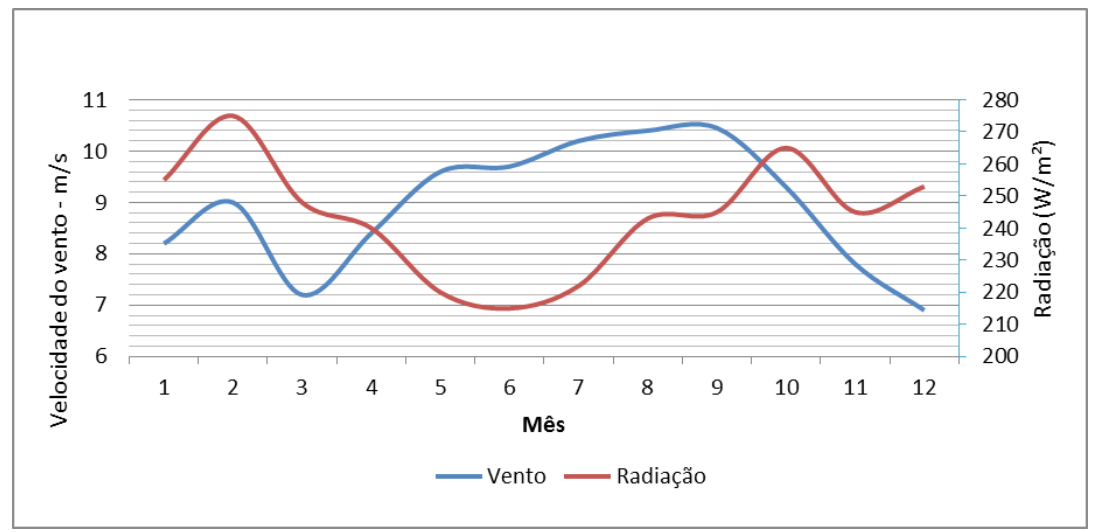

Figura 9. Complementaridade solar e eólica anualmente [11].

\section{Viabilidade e impactos da geração eólica}

O crescente aumento de parques eólicos com grande capacidade de geração torna a participação da energia eólica cada vez mais importante, como um complemento limpo e eficaz na matriz elétrica mundial, predominantemente baseada em combustíveis fósseis e, assim, reduzindo a emissão de $\mathrm{CO}_{2}$ em milhões de toneladas. Entretanto, existem impactos relevantes na inserção da geração eólica no sistema elétrico, pois esta pode afetar as características de tensão, frequência, níveis de curto circuito e a qualidade de energia da rede.

\subsection{Qualidade de energia elétrica}

Não há um sistema elétrico que não apresente nas suas características desvios do nível de tensão e forma de onda. Esses desvios determinam a qualidade de energia produzida e fornecida. No Brasil, os procedimentos do Operador Nacional do Sistema Elétrico (ONS) definem os padrões de qualidade de energia. O efeito na rede elétrica pela injeção de potência gerada por aerogeradores é mais severo, de- 
Revista Ciências Exatas e Naturais, Vol.14, n², Jul/Dez 2012

vido à variação da velocidade do vento. Essa intermitência pode causar variações de tensão em redes fracas, flutuações de tensão no domínio do tempo, sobretensões, harmônicas e picos de tensão. Os geradores de velocidade variável possuem conversores estáticos, que causam variação de tensão e picos de potência ativa (Figura 10) e reativos. Sendo assim, a qualidade da energia produzida pelo parque eólico deve considerar:

- Variação da potência da turbina eólica;

- Potência reativa e fator de potência;

- Transitórios de chaveamento elétrico;

- Flutuação de tensão;

- Harmônicos de tensão e corrente.

Para determinar a qualidade de energia, deve ser considerada a operação normal, na qual o gerador está em funcionamento contínuo e conectado com a rede e a operação em condições especiais, que são os chaveamentos, ocorrendo em um período pequeno de tempo. Nas duas formas de operação devem-se investigar os parâmetros citados anteriormente $[13,14]$.

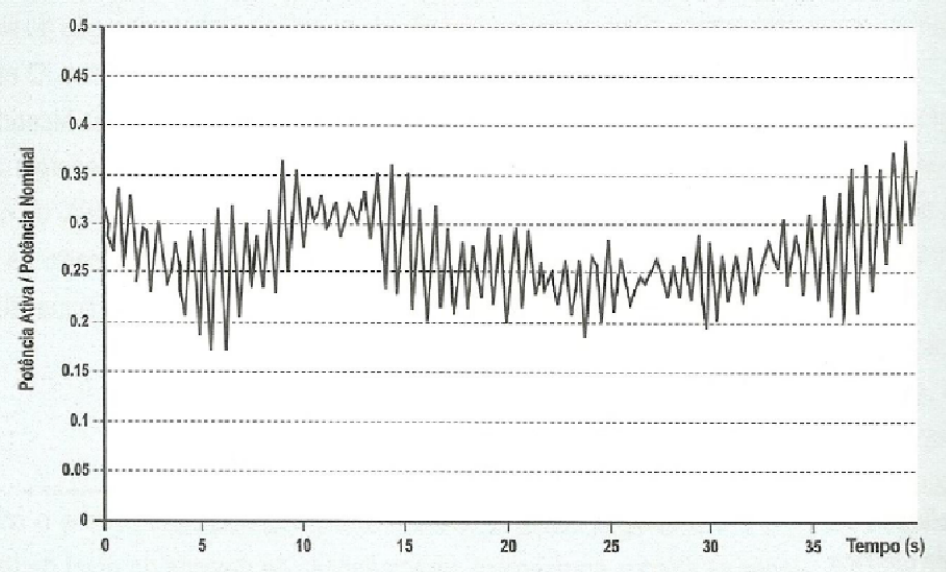

Figura 10. Oscilação de potência ativa em um gerador de velocidade fixa [9]. 
Os impactos da geração de centrais eólicas com relação à qualidade de energia estão associados principalmente à questão do efeito flicker e de harmônicos. Com a instalação de centrais eólicas de grande porte e em quantitativos expressivos, estimase que a influência dos sistemas eólicos passe a produzir impactos no desempenho dinâmico global do Sistema Interligado Nacional [15].

\subsubsection{Variação de tensão}

Definem-se como variações de tensão as mudanças no valor RMS das tensões ocorridas em um determinado espaço de tempo. Suas principais causas são as variações nas cargas ou na geração. A regulação de tensão no sistema elétrico representa um conjunto de ações do operador para manter as tensões dentro de faixas preestabelecidas, para fazer frente às variações de carga e, em consequência, de carregamento do sistema de transmissão e naturalmente, ao injetar potência em diversos pontos do sistema, as centrais geradoras eólicas interferem nesse processo impactando de alguma forma nesse problema [15].

A geração de energia em um parque eólico varia constantemente e não depende somente das condições do vento, pois o parque pode, devido a um desligamento de emergência, passar de sua carga nominal para vazio, ou a situação reversa, do vazio para carga nominal quando é ligada em condições de ventos favoráveis. As máquinas síncronas podem ser ligadas sem ocasionar qualquer perturbação à rede, desde que as providências, para que não haja trânsito de energia ativa e reativa, sejam tomadas.

\subsubsection{Flutuação de tensão}

A flutuação do valor eficaz da tensão é a variação aleatória e rápida da tensão alternada. A variabilidade dos ventos com suas turbulências, o efeito sombra devido à localização que os aerogeradores se encontram, como em fileiras mais afastadas em relação ao vento predominante, e os erros das máquinas, no que se refere ao passo da pá e da mudança de direção, colocam os geradores eólicos como uma das principais fontes de flutuação de tensão da rede. 


\subsubsection{Harmônicas}

A presença de harmônicos significa que há uma distorção na forma de onda de tensão ou de corrente, com frequências múltiplas da fundamental. A série de Fourier pode representar essas deformações na onda senoidal, que geralmente trazem alguns efeitos, como perdas adicionais, sobrecargas de capacitores, aquecimento de motores, entre outros. Os parques eólicos, onde os geradores são de velocidade variável, possuem inversores, eles causam essas distorções devido ao sistema possuir uma característica não linear. Já turbinas com velocidades fixas não ocasionam esse problema. Os limites de distorção harmônica, no Brasil, são definidos também pelo Procedimento de Rede - ONS, apresentado na tabela 4 [16].

Tabela 4. Limites de distorção harmônica de tensão no Brasil [16].

\begin{tabular}{ccc}
\hline Ordem dos Harmônicos & Limite para $\mathrm{V}<69 \mathrm{kV}$ & Limite para $\mathrm{V} \geq 69 \mathrm{kV}$ \\
\hline Ímpares: 3 a 25 & $1,50 \%$ & $0,60 \%$ \\
Ímpares: $\geq 27$ & $0,70 \%$ & $0,40 \%$ \\
Pares: todos & $0,60 \%$ & $0,30 \%$ \\
DTHT & $3,00 \%$ & $1,50 \%$ \\
\hline
\end{tabular}

\subsubsection{Energia reativa}

Nos geradores que possuem velocidade constante, a energia reativa é compensada pelo banco de capacitores de autoexcitação, ficando assim, com o fator de potência superior a 0,96 . O controle da energia reativa inserida na rede depende das características de cada uma, já que está relacionada com a capacidade de curto-circuito e de sua impedância. Essa energia reativa injetada depende sempre do valor da potência ativa inserida na rede elétrica e, em uma situação de potência ativa nominal, deve-se inserir na rede o valor máximo de potência reativa permitida pelo código de rede.

A energia reativa é necessária, porque o gerador eólico pode afetar os níveis de tensão. A variação de tensão permitida no Brasil, para linhas de transmissão com níveis de tensão entre $13,8 \mathrm{kV}$ e $440 \mathrm{kV}$ é de $5 \%$ e também deve manter o fator 
de potência dentro da faixa estabelecida pelo Procedimento de Rede - ONS, como mostra a tabela 5 [16].

Tabela 5. Fator de Potência Operacional nos Pontos de Conexão [16].

\begin{tabular}{cc}
\hline Tensão Nominal do Ponto de Conexão & Faixa de Fator de Potência \\
\hline $\mathrm{Vn} \geq 345 \mathrm{kV}$ & 0,98 indutivo a 1,0 \\
$69 \mathrm{kV} \leq \mathrm{Vn} \leq 345 \mathrm{kV}$ & 0,95 indutivo a 1,0 \\
$\mathrm{Vn} \leq 69 \mathrm{kV}$ & 0,92 indutivo a 0,92 capacitivo. \\
\hline
\end{tabular}

Nos geradores de velocidade variável, o fator de potência fica em torno de 1,0, uma vez que a energia reativa é controlada pelo inversor.

\subsubsection{Transitório}

Transitórios são os significativos desvios de curta duração das tensões e correntes em relação aos seus valores nominais, na ordem de microsegundos ( $\mu$ s) ou milisegundos (ms). A geração eólica origina o transitório na rede, que ocorre predominantemente no momento da ligação ou desligamento dos aerogeradores de velocidade fixa. Com a velocidade do vento em um patamar mínimo necessário para a geração, o aerogerador inicia sua sequência de ligação à rede elétrica. Então a velocidade do gerador aumenta até atingir valores próximos da velocidade de sincronismo e então é ligada a rede.

Porém, na sequência de ligação, há picos de correntes que alcançam duas vezes o valor nominal do aerogerador, o que pode modificar a tensão da rede. O transitório causa distúrbios em equipamentos sensíveis, como eletrônicos, interligados na mesma rede elétrica.

\subsection{Controle de frequência}

A frequência é uma grandeza que deve ser mantida dentro de uma faixa muito estreita de utilização. A frequência está ligada ao equilíbrio das potências geradas e consumidas, considerando as perdas na rede. Como não há possibilidade de armazenar energia elétrica, a geração tem o papel de manter esse equilíbrio constan- 
temente, já que não é possível controlar o consumo de energia. Se a geração não atender à demanda do consumo, a frequência pode sofrer uma queda no tempo e, com isso, uma diminuição na faixa de $1 \mathrm{~Hz}$ já tornaria a situação alarmante, com possibilidades de um apagão.

Porém, é praticamente impossível que o consumo seja igual à geração momentaneamente. Assim, as matrizes geradoras variam automaticamente sua potência, a fim de gerar a energia necessária à rede e manter a frequência em seu valor nominal. Esse processo é realizado através do sistema de controle de frequência, que consiste em dois níveis: controle primário e secundário.

O controle primário situa-se no local dos grupos geradores, realizando o controle da geração até que a geração e a demanda se igualem e a frequência estabilize, atuando em ciclos de 1 a 30 segundos. Como o controle primário não retorna a frequência ao valor nominal, o controle secundário atua a partir do centro de controle, com intervalos de 10 a $15 \mathrm{~min}$.

Os parques eólicos, mesmo em regimes normais de funcionamento, podem variar sua potência gerada de $10 \%$ a $15 \%$ da capacidade instalada em intervalos de 15 minutos e, em condições extremas, esses valores podem variar de forma muito abrupta, ocasionando no sistema elétrico uma defasagem entre a geração e o consumo.

Em função dessas variações na geração eólica, deve-se levar em conta a rede em que ela será inserida, pois redes pequenas e fracas são mais susceptíveis aos desvios de frequência e assim, coloca-se em risco a rede em situações de maiores diferenças entre a geração e a demanda. As redes de grande porte não sofrem tanto com a intermitência da geração eólica, devido à compensação por outras fontes geradoras interligadas ao mesmo sistema.

Em caso de desequilíbrios entre a potência total dos geradores síncronos e a potência total consumida pelas cargas, podem-se realizar mudanças nas velocidades das unidades geradoras, adequando a sua necessidade à frequência nominal. Em casos em que haja diminuição da frequência os aerogeradores devem responder com um aumento de potência injetada na rede e vice-versa.

Os avanços da geração eólica integrada às redes elétricas de energia, basicamente 
por aerogeradores de velocidade variável, tendem a tornar os sistemas mais instáveis, devido a este sistema possuir os seus métodos de controle que praticamente desacoplam as grandezas elétricas das mecânicas, e assim, dificultam que o rotor e o aerogerador respondam as variações de frequência da rede. A geração eólica tem como característica principal a sua flutuação que depende das condições do vento e que precisa ser compensada para proporcionar uma alimentação estável ao sistema [17].

Há também uma regulação secundária que anula as diferenças entre a carga e a geração e, consequentemente anulam, os desvios de frequência que a regulação

primária das máquinas não consegue realizar. Conforme a carga se altera continuamente, os controles secundários nos geradores regulam suas gerações automaticamente para o controle contínuo da frequência. A regulação secundária deve ocorrer, de forma corretiva, apenas na rede em que foi detectada a variação da carga ou geração, resolvendo as ocorrências sem afetar redes próximas.

A regulação secundária, no que se refere aos parques eólicos, tem a função semelhante ao controle aplicado em outras matrizes geradoras, alterando as operações dos aerogeradores, a fim de garantir que o operador do parque possa realizar as operações necessárias para a estabilidade da rede.

Os códigos mundiais relacionados à qualidade da rede elétrica solicitam que os parques eólicos tenham uma resposta de frequência para contribuir com a regulação do sistema de frequência da rede.

\subsubsection{Tolerância de frequência e requisitos operacionais}

Os códigos de redes em geral, estipulam tolerâncias e requisitos para a operação dos sistemas de frequência e tensão, com intuito de evitar as suas consequências decorrentes, más regulações. Frequências fora dos valores nominais podem ocasionar superaquecimento dos aerogeradores, diminuindo o tempo de vida de suas isolações e causando danos aos equipamentos de eletrônica de potência da máquina.

Há anos, quando a geração eólica não tinha tanta expressão nas matrizes elétricas mundiais, os parques eólicos eram desligados da rede em situações em que a frequência sofresse uma queda súbita, a fim de se protegerem de possíveis danos. 
Porém, com a criação de parques cada vez maiores e a relevância da geração eólica para a rede, a sua retirada da rede provoca uma diminuição ainda maior da frequência, e assim, a diminuição da capacidade de recuperação do sistema. Com isso, os operadores do sistema, com o intuito de reestabelecer mais rapidamente as condições de frequência da rede, mantêm os aerogeradores ligados ao sistema em casos de perturbações, porém funcionando em um uma gama de valores de frequência mais altos.

\subsection{Controle de tensão}

A tensão, diferentemente de frequência, é de caráter local e assim seu valor em um determinado nó só pode ser controlado pelo próprio nó ou por sua vizinhança direta. A diferença de tensão ocorre através da circulação de uma corrente entre dois nós em um ramo e ela não pode sair de uma faixa de tensões como base o valor nominal.

O controle dessa tensão deve-se às capacitâncias, reatâncias e indutâncias dos componentes da linha, como os transformadores, linhas e cabos. No nível local, as variações de tensão são o principal problema de sistemas eólicos. Padrões de tolerância de variação dos níveis de tensão estão estabelecidos em $\pm 10 \%$, porém variações rápidas e em redes fracas, tornam-se um incômodo em valores muito menores [18].

Geradores eólicos interferem no trânsito de energia elétrica, e assim, afetam as tensões nos nós. Como em redes de transmissão as tensões dos nós são controladas pelas centrais convencionais de geração elétrica, há a necessidade delas possuírem a capacidade de controlar as tensões nos nós, para compensar os impactos da geração eólica e, portanto, manter níveis aceitáveis de tensões.

Um aerogerador interligado a uma rede de distribuição pode ocasionar trânsitos de energia, tensões nos nós e afetar as correntes. Com essas características, os dispositivos instalados na rede de distribuição podem gerar problemas em compensar os impactos do gerador eólico nas tensões dos nós, o que pode ocasionar valores fora dos aceitáveis. A flutuação de tensão devido à variação da velocidade de vento torna-se um fator limitador da capacidade instalada de sistemas eólicos [18]. 


\subsection{Impactos da inserção da energia eólica no controle de tensão em redes de transmissão}

Como mencionado, nas redes de transmissão as grandes centrais elétricas convencionais sempre realizaram o controle de tensão. Contudo, a expansão eólica, entre outros novos tipos de geração de energia, modifica aos poucos as estratégias do controle centralizado, deixando de ser competência somente das grandes centrais elétricas, resultando em uma responsabilidade maior a empresas independentes e descentralizadas, passando parte dela da rede de transmissão para distribuição. Esses fatores contribuem para a dificuldade do controle de tensão devido à menor influência das fontes convencionais da regulação da rede.

\subsection{Impactos da inserção da energia eólica no controle de tensão em redes de distribuição}

Os sistemas de distribuição possuem um controle de tensão realizado por ajustes na relação de transformação de transformadores e dispositivos em que consomem ou produzem potência reativa.

A produção descentralizada ocasionada por novas fontes de energia também afeta a distribuição de energia, principalmente afetando o trânsito de energia, pois fontes de energias como a eólica e a solar fotovoltaica, que não são controláveis, podem gerar potências que não correspondem com a necessária, aumentando a variação das correntes nos ramos e as tensões nos nós.

Sem a geração de energia descentralizada, os valores máximos e mínimos de corrente em certo ramo da rede dependiam apenas dos valores máximos e mínimos da demanda, porém com a descentralização dependem também da potência fornecida pelos geradores em que agora são estabelecidos pela máxima demanda e mínima geração e mínima demanda e máxima geração.

Em uma análise teórica, a inserção de mais geradores na rede de distribuição aumentaria o controle de tensão, porém na maioria dos casos os geradores que são ligados às redes de distribuição não têm a mesma capacidade de controle de tensão que os geradores interligados às redes de transmissão, em função de serem geradores 
que nem sempre possuem a capacidade de variar a potência reativa gerada.

Há uma série de benefícios na expansão da geração descentralizada, principalmente por fatores ambientais, devido aos problemas enfrentados pelo planeta nas últimas décadas ou a redução de riscos em níveis de investimento. Porém os problemas com controles de tensão e frequência nas redes elétricas são bastante relevantes e devem ser considerados.

Para isso, existe uma série de pesquisas para as melhorias da qualidade de energia, tanto nas matrizes centralizadas como descentralizadas. A inserção de um número maior de equipamentos de controle de tensão, como cargas de impedância constante e um número maior de transformadores com razão de transformação unitária com a função apenas de controle de tensão nos nós, pode melhorar a qualidade de energia nas gerações centralizadas. Porém a implantação de sistemas de controle exige significativos investimentos. Nas gerações descentralizadas, a melhor solução seria exigir que os geradores auxiliassem no controle de tensão, apesar dos investimentos agregados para isso. Um aumento da geração eólica distribuída introduz no sistema uma maior complexidade do controle, proteção e manutenção [18].

As empresas concessionárias das redes de distribuição necessitam de se equipar de ferramentas de análise para avaliação do impacto dos sistemas eólicos à rede, sob o ponto de vista da confiabilidade do atendimento, qualidade da tensão e estabilidade da operação, considerando as características dessa fonte de geração de energia [17].

\subsection{Capacidade de suporte à afundamento de tensão}

A ocorrência de afundamentos de tensão pode gerar riscos à segurança de parques eólicos, porque implica perda de um volume significante da produção eólica, principalmente ocasionados pelos aerogeradores mais usuais que não possuem capacidade para continuar funcionando na sequência de uma falha na rede. Para solucionar essas ocorrências, constituem-se códigos da rede com as exigências mínimas, para reger de forma segura a geração eólica. Na Europa, onde a geração eólica tem uma penetração grande na matriz elétrica, existem códigos de redes que exigem condições para funcionamentos dos parques geradores, códigos que devem ser planejados para o Brasil em um espaço curto de tempo em virtude do avanço da geração 
eólica.

$\mathrm{Na}$ questão das faltas, deve-se exigir que invariavelmente os parques eólicos, principalmente aqueles ligados às redes de alta tensão, resistam as quedas de tensão até determinada percentagem da tensão nominal em um determinado período de tempo. Existem aerogeradores que apresentam recursos de controle capazes de garantir um desempenho satisfatório durante e após as falhas e atender aos requisitos de afundamentos momentâneos de tensão [15].

Requisitos necessários e já existentes em outros países solicitam uma restauração das potências ativas e reativas em um curto espaço de tempo e impõem um aumento da geração de energia reativa durante os distúrbios na rede para o suporte da sua tensão. Em âmbito geral, são normas que especificam períodos mínimos de tempo em que o aerogerador deve se manter em serviço, dependendo esse tempo do valor de tensão do afundamento de curto circuito. Essas medidas têm como objetivo proteger os vários equipamentos que compõem o gerador, evitando assim esforços mecânicos elevados nas caixas de velocidades do conjunto e a sobrecarga nos equipamentos eletrônicos.

\section{Análise da geração em outros países}

A geração eólica já se disseminou no mundo, havendo muitos investimentos globais nessa área de geração de energia, sendo os Estados Unidos e a China os países que mais investem. Porém os países europeus são quem mais possuem percentualmente em sua matriz energética esse tipo de geração e, consequentemente, os que possuem estudos mais avançados no que se refere à qualidade de energia e impactos da inserção da energia eólica na rede. A Dinamarca, por exemplo, que é um país pioneiro na instalação de parques eólicos, lidera com a maior percentagem de geração através dos ventos, com aproximadamente $25 \%$ de sua matriz elétrica. Espanha e Portugal apresentam matrizes onde a energia eólica corresponde a aproximadamente 15\% [11]. Esses valores de penetração de energia eólica na geração do país, para muitos especialistas, são os valores máximos admissíveis para uma operação segura e previsível da rede elétrica.

A maior potência eólica instalada na Europa está na Alemanha, seguida de Es- 
panha e Dinamarca, também havendo potência acumulada acima de $1 \mathrm{GW}$ em 10 países dos 27 que compõem a União Europeia. Com isso, a energia eólica representa aproximadamente $8 \%$ da geração de energia instalada em toda Europa. Como exemplo, considera-se a Espanha, que teve 14\% de sua geração em 2011, proveniente de geradores eólicos, conforme a figura 11 [19]. A potência acumulada instalada no país é da ordem de 22 GW em 2012 o fator de capacidade foi da ordem de 24\% [19].

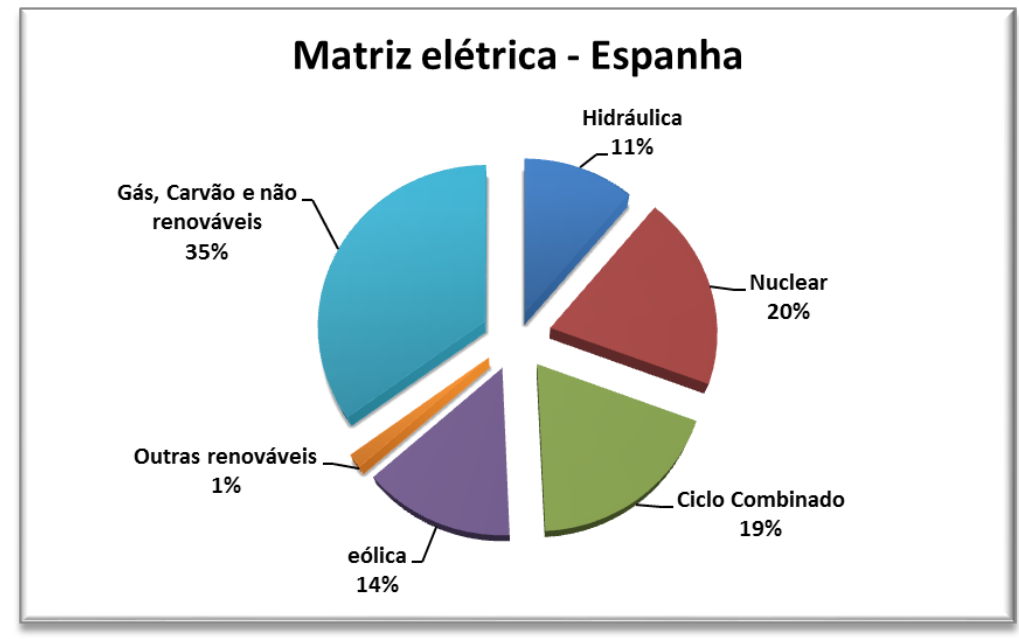

Figura 11. Matriz elétrica da Espanha [19].

Esse crescimento segue há anos na Espanha, como em toda Europa e nos países mais desenvolvidos ou em desenvolvimento, diferentemente do Brasil que está no mercado eólico em nível de geração para o sistema interligado há seis anos. Os sistemas eólicos, na Espanha, superaram a barreira de 1 GW de potência em 1999 [19].

A Europa, como já citado, é quem possui maior percentual de geração elétrica em suas matrizes, porém a experiência adquirida com o tempo e penetração da geração eólica e seus impactos causados às redes, implicou que cada país europeu elaborasse um código de rede próprio para a geração eólica, a fim de controlar, de forma adequada e mais confiável, seus sistemas que se tornam mais vulneráveis com um percentual cada vez maior desse tipo de geração. Esses códigos estabelecem requisitos, para que o parque seja inserido na rede, como os seguintes itens: 
- Controle ativo de potência;

- limites de frequência e tensão;

- controle de tensão;

- proteção dos parques eólicos contra perturbações ou defeitos da rede;

- modelização e verificação dos parques eólicos;

- comunicação e controle externo do operador da rede.

Cada país a partir das características de sua rede desenvolveu seu código com valores específicos para cada item descrito, porém, é de senso comum que exista um limite para a inserção eólica nas redes elétricas para que seja possível haver um controle estável e seguro do sistema elétrico como um todo. Esses valores são muito discutidos e dependem de cada rede, como a localização do parque perante a rede e confiabilidade da rede a serem inseridos os geradores eólicos. Os valores estão entre $15 \%$ e $20 \%$.

\section{Análise e discussão dos resultados}

O Brasil segue a tendência mundial no uso das energias renováveis, possuindo um potencial gigantesco a ser explorado. As regiões Sul e Nordeste destacam-se fortemente do restante do país e atualmente só existem parques interligados ao SIN nessas regiões. O nordeste possui ótimas condições de geração em toda sua faixa litorânea, atraindo grandes investimentos. A região também se destaca pela potência instalada já vendida e ainda apresenta a vantagem da complementaridade com a geração hídrica, auxiliando na conservação de reservatórios de água nos períodos de estiagem. A região Sul, por sua vez, tem seu principal destaque no litoral gaúcho, com ventos acima da média mundial para geração eólica e grandes projetos de parques para instalação nos próximos anos, principalmente no extremo sul.

Além da complementaridade da geração eólica e hídrica no nordeste, devido a sazonalidades de ambos os sistemas, a geração hídrica é utilizada como geração base para a geração eólica, o que acarreta em uma confiabilidade maior ao sistema elétrico brasileiro. Outra complementaridade bastante interessante é a geração eólica juntamente com a geração solar que, além das sazonalidades anuais referentes 
à radiação solar e a força dos ventos, há uma complementaridade diária em ambas as gerações, auxiliando também para que haja um sistema elétrico mais confiável. Contudo, a geração solar no Brasil ainda está em fase de estudo para implantação de políticas de incentivo e ainda não existem unidades geradoras de grande porte ligadas ao sistema nacional.

O crescente avanço eólico, em um período reduzido de tempo, oferece um desafio ao sistema interligado brasileiro uma vez que esse tipo de geração apresenta intermitência e imprevisibilidade. Isso implica a necessidade de um planejamento mais amplo e específico na área eólica, com medidas adequadas para as situações adversas que podem ocorrer. Como base, pode-se considerar os planejamentos europeus, em que suas matrizes elétricas possuem percentuais entre $12 \%$ e $20 \%$ de participação em determinados países, o que lhes confere experiências e bases reais dos efeitos da grande inserção da geração na rede elétrica local. Para inserção de elevadas quantidades de energias provindas da geração eólica, garantindo que não haja comprometimento nas condições de segurança e confiabilidade, é necessário analisar uma série de fatores capazes de influenciá-la.

A rede deve ser planejada para suportar as grandes mudanças de trânsito de energia provocadas pela geração descentralizada e sua variação no tempo, sendo também necessário considerar a utilização da geração eólica como complementar e nunca como energia garantida, uma vez que ela não produz eletricidade de forma contínua. É preciso que o controlador da rede esteja pronto para despachar quaisquer alterações que ocorram no sistema, a fim de controlar o trânsito de potência, realizando melhores previsões para a produção eólica. Também é de extrema importância exigir que os parques eólicos estejam preparados com geradores capazes de:

- Continuarem ligados mesmo que haja variações significativas de tensões ou de frequências na rede;

- continuarem ligados, em certos períodos de tempo, quando houver afundamentos de tensões causadas por defeitos;

- durante os curtos-circuitos, injetar energia reativa na rede, a fim de minimizar 
os seus efeitos sobre a tensão;

- após defeitos na rede retomar a geração de energia ativa, conforme as taxas de crescimento definidas;

- conforme solicitado pelo operador da rede, restringir a potência ativa introduzida ao sistema;

- colaborar com a estabilidade da tensão do sistema, fornecendo ou absorvendo energia reativa;

- colaborar com a estabilidade da rede diminuindo a energia ativa injetada no sistema caso a frequência suba;

- apresentar disponibilidade de ser monitorado e controlado remotamente.

A criação de um código atual para a instalação de parques eólicos será necessária, para que o funcionamento do sistema possa crescer, sem que haja quaisquer problemas de segurança ou falha. Deve destacar a importância dos softwares para simulação, planejamento, dimensionamento e previsibilidade dos parques eólicos, os quais direcionam os investimentos e os projetos para áreas que realmente disponibilizem condições adequadas para seu funcionamento.

\section{Conclusão}

Este trabalho apresentou um panorama da energia eólica no Brasil e no mundo, a potencialidade de integração com outras fontes de energia e analisou os impactos da inserção da geração eólica nas redes elétricas, avaliando a capacidade das redes em diversas situações como a variação de tensão e de frequência, o controle de tensão e de frequência, transitório, harmônicas, e sobrevivência afundamentos de tensão. Uma breve descrição da participação da energia eólica na matriz energética da Espanha também foi apresentada. O Brasil é um mercado com muita capacidade de expansão e com grande folga em sua matriz energética, permitindo esse avanço. As regiões Sul e Nordeste possuem as melhores perspectivas possíveis para esse crescimento e devem se preparar para uma inserção eólica segura nas redes elétricas, planejando-as adequadamente e exigindo que os parques tomem medidas, para realizar os controles necessários, a fim de disponibilizar a energia eólica de forma segura 
e confiável. Por parte governamental, conclui-se que é necessário que um código nacional específico seja criado com a finalidade de definir normas e conceitos a serem seguidos na instalação e colocação do parque ao sistema interligado nacional e, periodicamente, atualizá-lo considerando as características da rede na qual está inserida e os avanços nos aerogeradores e trabalhar na melhoria da infraestrutura necessária para a instalação de parques eólicos.

\section{Referências}

[1] BERMANN, C. Energia no Brasil: Pra quê? Pra quem? Crise e alternativas para um país sustentável. 2 ed. São Paulo. Editora Livraria da Física. FASE, 2001.

[2] IEA - International energy agency. World: Statistic. Disponível em http://www.iea.org/stats/pdf_graphs/29TPESPI.pdf. Acesso em Ago/2012.

[3] MME - Ministério de Minas e Energia. Balanço energético nacional. Rio de Janeiro, 2012. Disponível em https://ben.epe.gov.br/BENResultadosPreliminares2012.aspx. Acesso em Ago/2012

[4] ANEEL - Agência Nacional de Energia Elétrica. Banco de informação de geração. Disponível em http://www.aneel.gov.br/aplicacoes/capacidadebrasil/OperacaoCapacidade Brasil.asp. Acesso em Out/2012.

[5] ONS - Operador Nacional do Sistema Elétrico. Histórico da operação - Geração de energia. Disponível em: http://www.ons.org.br/historico/geracao_energia.aspx. Acesso em Ago/2012.

[6] Brazil Energy. Perfil do setor. Rio de Janeiro, 2012. Disponível em http://brazilenergy.com.br/portfolio/brazil-wind/perfil-do-setor. Acesso em Set/2012.

[7] GWEC - Global Wind Energy Council. Analysis of the regulatory 
framework for wind power generation in Brazil. 2012. Disponível em http://www.gwec.net. Acesso em Set/2012.

[8] ABEEólica - Associação Brasileira de Energia Eólica. Com a força dos ventos a gente vai mais Longe. São Paulo, 2012. Disponível em http://www.abeeolica.org.br. Acesso em Set/2012.

[9] SOARES, L. T. Planejamento e implementação de um parque eólico. Fortaleza, 2010. Disponível em http://www.dee.ufc.br/anexos/TFCs/20101/Luciane\%20T\%20Soares.pdf.

[10] AMARANTE, O. A. C.; BROWER, M.; ZACK, J.; SÁ, A. L. Atlas do potencial eólico brasileiro. 2001. Brasília 2001.

[11] ABEEólica - Associação Brasileira de Energia Eólica. Potencialidades da energia solar associada à geração eólica. São Paulo, 2012. Disponível em http://www.abeeolica.org.br. Acesso em Set/2012.

[12] CASTRO, N. J.; BRANDÃO, R.; DANTAS, G. A. Considerações sobre a ampliação da geração complementar ao parque Hídrico Brasileiro. Textos de Discussão do Setor Elétrico ${ }^{0} 15$. Rio de Janeiro, 2010. Disponível em http://www.nuca.ie.ufrj.br/gesel/tdse/TDSE15.pdf. Acesso em Set/2012.

[13] DUTRA, R.M. Energia eólica, princípios e Tecnologia. Centro de Referências para Energia Solar e Eólica Sérgio de Salvo Brito (CRESESB), Rio de Janeiro. 2009.

[14] CUSTÓDIO, R. S. Energia eólica para produção de energia elétrica. Eletrobrás. Rio de Janeiro, 2009.

[15] RAMOS, A.; TAVARES, C.; SENA, D. Impacto da geração distribuída eólica nos sistemas de distribuição e transmissão. O Setor Elétrico. v. 75, p. 50-59, 2012.

[16] ONS - Operador nacional do sistema elétrico. Procedimentos de rede. Rio de Janeiro, 2006. Disponível em http://www.ons.org.br. Acesso em Ago/2012. 
Revista Ciências Exatas e Naturais, Vol.14, n², Jul/Dez 2012

[17] SILVA, M. S.; SCHWARZ, H.; PFEIFFER, K. Integração da geração eólica nas redes de transmissão e distribuição. O Setor Elétrico. v. 77, p.46-53, 2012.

[18] SILVA, N. F. Fontes de energias renováveis complementares na expansão do setor elétrico brasileiro: O caso da energia eólica. Programa de Pós-Graduação em Engenharia da Universidade Federal do Rio de Janeiro. 2006.

[19] REE - Red Eléctrica de España. Operacion del Sistema. España, 2012. Disponível em https://www.ree.es/operacion/operacion_sistema.asp. Acesso em Fev/2013. 